\title{
Variation of hardness, microstructure, and Laves phase distribution in direct laser deposited alloy 718 cuboids
}

\author{
Erica L. Stevens ${ }^{\mathrm{a},+}, J^{2}$ akub Toman ${ }^{\mathrm{a}}$, Albert C. To ${ }^{\mathrm{a}}$, Markus Chmielus ${ }^{\mathrm{a}, *}$ \\ a Department of Mechanical Engineering and Materials Science, University of Pittsburgh, \\ Pittsburgh, PA 15261, USA \\ + email: ericastevens@pitt.edu \\ * corresponding author: chmielus@ pitt.edu
}

\begin{abstract}
Property anisotropy and its unpredictability in direct laser-deposited material is a drawback to this additive manufacturing method. In this study, direct laser deposition was used to build threedimensional cuboids of Ni-based superalloy 718, which were examined with microscopy, and analyzed for hardness trends with contour mapping. Secondary electron and backscatter electron contrast imaging were used in conjunction with electron backscatter diffraction to understand microstructure. It is found that hardness decreased with increasing height and linear energy used during deposition. Also, the hardness of the inner hatching was higher than the outer contour, in both planar and cross-sectional surfaces. After an examination of grain structure and phase distribution, it is proposed that the hardness trends are caused by a combination of detrimental Laves phase and strengthening $\gamma^{\prime \prime}$ phase distribution.
\end{abstract}

\section{Keywords}

Additive manufacturing; linear energy; hardness mapping; segregation; Laves phase; melt pool boundary

\section{Introduction}

Additive manufacturing (AM) is being developed due to its capacity to create complex part geometries, include limited production steps and parts, and produce minimal waste [1-3]. One AM method for depositing structural metals is Laser Engineered Net Shaping (LENS®) direct laser deposition (DLD), a process which creates a melt pool with a laser and deposits powder through nozzles towards the melt pool, some of which adds to its volume [4-6]. Not needing a full bed of powder and having the freedom to deposit material selectively allows for the construction of traditionally impossible part geometries, such as complex cooling channels and turbine parts $[5,7]$. One significant concern for such parts is the effect of the AM process on the structure and resulting properties, so there is much research relating microstructure and mechanical properties of important structural AM metals such as Ti-6Al-4V, alloy 625, and steels fabricated by various methods [8-13]. DLD causes the part to experience a substantial amount of thermal cycling, which directly affects the formation of the microstructure upon cooling $[14,15]$. Thus, it is important that microstructures of DLD-manufactured parts are examined, understood, and eventually linked to particular deposition parameters in order to better engineer desired microstructures and induce required mechanical properties.

As with any metal manufacturing methods, the microstructure of DLD-fabricated parts is highly sensitive to thermal history, controlled by process parameters [16]. Since processing parameters 
(e.g. laser power, layer height, hatch separation distance) and their combination affect the build in different ways, it is a challenge to predict final as-built microstructures. Many experiments have been designed to model and examine microstructures based on parameters, but translating this knowledge to larger, more complete parts is a continuing research effort. In general terms, it has been found that a slower solidification front velocity encourages a columnar microstructure, while a faster solidification front velocity encourages equiaxed grains [17-19].

Alloy 718 is a nickel-based superalloy, used in the aerospace industry and for other hightemperature applications [20, 21]. Alloy 718 is primarily composed of a face-centered cubic (FCC) nickel crystal structure ( $\gamma$-phase), which provides favorable toughness and ductility at high temperature [22]. Primary strengthening phases are FCC $\gamma^{\prime}\left(\mathrm{L}_{2} \mathrm{Ni}_{3}(\mathrm{Al}, \mathrm{Ti})\right.$ ) and bodycentered tetragonal (BCT) $\gamma^{\prime \prime}\left(\mathrm{D}_{22} \mathrm{Ni}_{3} \mathrm{Nb}\right)$. Metastable $\gamma^{\prime \prime}$ is prevalent only in nickel-iron superalloys such as alloy 718 that contain niobium, and it becomes the primary strengthener. However, the possibility for $\gamma^{\prime \prime}$ formation indicates the potential for the corresponding stable orthorhombic $\delta$ phase, which does not contribute to strengthening [23]. Two other important precipitates in alloy 718 are carbides $\left(\mathrm{MC}, \mathrm{M}_{23} \mathrm{C}_{6}, \mathrm{M}_{6} \mathrm{C}\right)$ the topologically close-packed (TCP) eutectic Laves phase which is known to be detrimental to strength as it depletes the elements necessary to form the strengthening phase $[22,24]$. Alloy 718 carbides can be rich in $\mathrm{Cr}, \mathrm{Ta}, \mathrm{Nb}$, $\mathrm{Ti}$, or Mo; Laves phase can be rich in $\mathrm{Nb}$ and $\mathrm{Mo}[21,25]$.

Research on various types of laser deposition of alloy 718, including DLD, direct laser fabrication (DLF), and selective laser melting (SLM), is aimed to improve microstructure, mechanical properties, and reliability [26-28]. Microstructure is important to understand, as it relates to properties. For example, grain size and aspect ratio are important for high-temperature superalloys because coarse grains columnar in the direction of loading can increase creep resistance [29]. Much research into DLD and DLF alloy 718 has focused on thin-walled structures $[25,27,30]$. The strengthening phase $\gamma^{\prime \prime}$ was identified in DLD alloy 718, and elemental segregation inducing formation of Laves phase and carbides occurred [25, 27].

The aim of the study is to obtain experimental data to support a more complete view of asdeposited DLD alloy 718 microstructure, and the effects on hardness and therefore mechanical properties in general. As much of the previous work has focused on thin-walled structures, this work on multi-dimensional parts will aid in the transition to understanding the structure and properties of larger Ni-based superalloy parts and the effect of DLD processing parameters. We provide a quantitative analysis of Laves phase distribution at melt pool edges, which serves as a coherent basis for understanding previously-observed and here-reported hardness trend. The influence of linear energy during the deposition process on the microstructure and mechanical properties is discussed as well.

\section{Experimental}

Samples were prepared with 44-150 $\mu$ m-diameter plasma-rotating electrode process (PREP) alloy 718 powder by the DLD process using a laser with a nominal spot size of $240 \mu \mathrm{m}$. The samples had varying laser travel speeds, with all other variables held constant, resulting in varying linear energies. 
10-layer square cuboids were manufactured using an Optomec LENS® 450 system. Samples were $10 \mathrm{~mm} \times 10 \mathrm{~mm} \times 3-5 \mathrm{~mm}$, and were deposited onto an alloy 718 substrate. A schematic of the manufacturing process and terminology can be seen in Figure 1. Each layer was printed in two stages: the contour and the hatching. The contour - the outer edge - was printed as one continuous bead, followed by the internal parallel lines of the hatching, each of which was deposited as a separate bead. Hatching lines were made at $0^{\circ}$ to the horizontal in the first layer, and were rotated counterclockwise by $45^{\circ}$ for each new layer. The hatching overlapped the contour slightly, resulting in an overbuilt contour. Samples were produced with laser travel speeds of $2.00 \mathrm{~mm} / \mathrm{s}, 3.33 \mathrm{~mm} / \mathrm{s}$, and $5.00 \mathrm{~mm} / \mathrm{s}$. Layer height in the software, hatch spacing, powder feed rate, and laser power were constant at $0.254 \mathrm{~mm}, 0.508 \mathrm{~mm}, 5 \mathrm{rpm}$, and $250 \mathrm{~W}$, producing linear energies - defined as laser power $(\mathrm{J})$ / laser travel speed $(\mathrm{mm})$ - of 125, 75, and $50 \mathrm{~J} / \mathrm{mm}$.

Samples were cut cross-sectionally. For electron backscatter diffraction (EBSD) and scanning electron microscopy (SEM), samples showing visible grain structure were polished with a final step of silica suspension, while all other SEM samples and hardness and optical microscopy (OM) samples had a final polishing step of alumina suspension. After metallographic preparation, the cross-section of the $125 \mathrm{~J} / \mathrm{mm}$ linear energy sample was swabbed for 10 seconds with Waterless Kalling's Etchant to reveal features of the microstructure for OM. The corresponding half of the same sample was cut parallel to the substrate into three slices: bottom, center, and top. Both the cross-sections and faces of all samples were examined using a JEOL JSM6610 SEM and ZEISS Sigma 500 VP SEM using secondary and backscatter electron contrast (BEC) imaging (where contrast arises from differences in atomic number - brighter areas indicate higher atomic numbers), as well as energy-dispersive x-ray spectroscopy (EDS). EBSD was performed on a Philips XL 30 SEM at 200x magnification for faces and 50x for cross-sections and post-processed with EDAX OIM software. All three samples were indented for hardness using a Leco Vickers microhardness tester on surfaces parallel and perpendicular to the substrate with a load of $500 \mathrm{gf}$ and a swell time of $10 \mathrm{~s}$. Indent sizes were measured using ImageJ software [31], and hardness was calculated using Equation 1 (ASTM E384):

$$
H V=\frac{1854.4 \cdot P}{d^{2}}
$$

where $H V$ is Vickers hardness number, $P$ is indentation load in gf, and $d$ is mean diagonal length of the indent in $\mu \mathrm{m}$.

Laves phase concentration was evaluated using ImageJ [31]. Each micrograph was enhanced in contrast only and thresholded manually to cover the Laves phase, then binarized so that the Laves phase and carbides appeared black. Binarized micrographs were then divided into a $15 \times 15$ grid of images, and the total area fraction of black in each image was recorded. Reassembly of the data and comparison with the original micrographs allowed for the distinction of the melt pool boundary during analysis.

\section{Results}

Figure 2 shows an exemplary build and an etched cross section. In each build, the layers were visible, as was the distinction between contour and hatching on the sample faces. Because of an 
overlap between the hatching and contour in each layer, the resulting build had overbuilt contours. In Figure 2b, the layers can be distinguished in the center (hatching) due to the melt pool locations; however, at the edges - where the hatching overlaps with the contour - layers become less distinct.

\subsection{Elemental analysis and precipitate identification}

BEC imaging such as that in Figure 4 showed a large-scale contrast that corresponds to the scan lines and the boundary between hatching and contour. Higher magnification revealed a dendritic microstructure with central areas of dark gray. Interdendritic regions were lighter in color, with interspersed areas of white, which had different morphologies. EDS area scan results given in Figure 3 show the distinct segregation of $\mathrm{Nb}$ and Mo to the interdendritic regions (all other elements were mostly uniform at the given magnifications).

White areas, shown in Figure 4, included Laves phase, approximately spherical particles (carbides), needle-shaped particles $(\delta)$, and dispersed light regions ( $\gamma^{\prime \prime}$-containing). Each region of distinct brightness was analyzed with EDS, and particles were identified by comparing morphology and composition to existing literature [16, 27, 28, 30, 32]. Transmission electron microscopy (TEM) results from similar samples in literature were examined closely to identify phases [27, 28, 32]. Laves phase and carbides have been well-documented in laser-deposited alloy $718[27,30,33]$. Figure 5a shows the $\delta$ phase, which is often plate-like but can appear in micrographs to be needle-shaped, appearing at stacking faults near the Laves phase [30, 34]. In Figure $5 \mathrm{~b}$, a lower magnification micrograph is shown for comparison to Tian et al. in order to confirm the $\gamma^{\prime \prime}$-containing regions, also identified by Amato et al. [27, 28].

The low and high magnification features, as well as the areas analyzed with EDS are shown in Figure 4, with average compositions given in Table 1. The Laves phase was enriched in $\mathrm{Nb}$ and Mo, compared to the $\gamma$ matrix. $\delta$ and $\gamma^{\prime \prime}$ regions had similar compositions, both also enriched in $\mathrm{Nb}$ and $\mathrm{Mo}$, with less $\mathrm{Nb}$ enrichment than the Laves phase. Carbides were identified with linescans showing increase in carbon across the particles; quantitative data is not provided for carbon content due to EDS limitations and C-containing contamination. Carbides were greatly enriched in $\mathrm{Nb}$, and also enriched in Mo and $\mathrm{Ti}$.

\subsection{Grain size and distribution}

Sample faces and cross sections were analyzed using EBSD. Shown in Figure 6 are two representative maps for the $125 \mathrm{~J} / \mathrm{mm}$ and $75 \mathrm{~J} / \mathrm{mm}$ samples of faces parallel to the substrate with the color coding indicating the out-of-plane orientation shown in the inverse pole figure. All samples showed mostly large, columnar grains that grew across region boundaries (e.g. hatchingcontour or hatching line boundaries). Some smaller grains were dispersed throughout the analyzed areas; in particular, the $75 \mathrm{~J} / \mathrm{mm}$ sample had a radial distribution of small grains in the bottom left corner of the micrograph, located near the hatching-contour boundary.

Cross-sectional (perpendicular to the substrate) EBSD data presented in Figure 7 was taken from the $125 \mathrm{~J} / \mathrm{mm}$ and $50 \mathrm{~J} / \mathrm{mm}$ samples. Due to the sample height differences, the $125 \mathrm{~J} / \mathrm{mm}$ sample scan spanned slightly over half of the total height, while the $50 \mathrm{~J} / \mathrm{mm}$ sample scan spanned almost the entire height. Both scans were taken in the highly-remelted area of the hatchingcontour boundary. Since the etched $125 \mathrm{~J} / \mathrm{mm}$ cross section had also been imaged using OM, 
EBSD data was overlaid on the optical micrograph of the etched cross section, and the result is displayed in Figure 7 along with the EBSD micrograph for the $50 \mathrm{~J} / \mathrm{mm}$ sample. Since the etching revealed the location of the edges of melt pools, the distribution can be interpreted in relation to the melt pool behavior. Compared with the $125 \mathrm{~J} / \mathrm{mm}$ samples, the $50 \mathrm{~J} / \mathrm{mm}$ build showed less distinct melt pools and layers, aside from several curved interfaces near the top of the scan.

Though each layer was different, many melt pools had grains along the bottom that were columnar towards the center of the melt pool, approximately perpendicular to the substrate. At the top of these melt pools existed smaller, more equiaxed grains. In both samples, an overall trend of increasing grain size and decreasing aspect ratio was observed by analyzing sections of the EBSD micrograph separately. Figure 7 also shows the region distinctions used for grain size analysis and the evolution from small equiaxed grains in the substrates to larger, columnar grains towards the top of the samples through plots of average grain size per region.

Grain size, reported as grain area, is plotted in red in Figure 8. For higher linear energy (125 $\mathrm{J} / \mathrm{mm}$ ), the substrate contained an average grain size of $340 \mu \mathrm{m}^{2}$, measured from 122 grains. The equiaxed region was found from 784 grains to have an average area of $850 \mu^{2}$. Columnar regions 1, 2, and 3 had average grain areas of $1380 \mu \mathrm{m}^{2}, 1580 \mu \mathrm{m}^{2}$, and $1800 \mu \mathrm{m}^{2}$ from 351, 387, and 233 grains, respectively. For lower linear energy $(50 \mathrm{~J} / \mathrm{mm})$, the substrate region contained 1340 grains and a calculated average area of $230 \mu \mathrm{m}^{2}$. The equiaxed region, containing 2614 grains, averaged a grain area of $470 \mu \mathrm{m}^{2}$. Columnar regions 1 and 2 had 1258 and 963 grains, averaging $880 \mu \mathrm{m}^{2}$ and $760 \mu \mathrm{m}^{2}$, respectively. Both samples had a trend of increasing grain size, though the Columnar 2 region for the $50 \mathrm{~J} / \mathrm{mm}$ sample showed a slight decrease from Columnar 1.

Grain aspect ratios (AR) - the ratio of the short to long diameter of a fitted ellipse - as computed by the OIM software are plotted in black in Figure 8, and are an indication of how equiaxed the grains are in the analyzed plane and region ( 1 - equiaxed, 0 - very columnar). The substrate region of the $125 \mathrm{~J} / \mathrm{mm}$ sample had an average AR of 0.51 . A decrease of AR to 0.42 is seen in the equiaxed region, with further decreases to 0.40 and 0.38 in the Columnar 1 and 2 regions. An increase to 0.43 occurred for Columnar 3 in the $125 \mathrm{~J} / \mathrm{mm}$ sample. For the $50 \mathrm{~J} / \mathrm{mm}$ build, the substrate and equiaxed regions showed AR of 0.50 and 0.46 , respectively. The AR continued to decrease into the columnar regions, which both showed an average of 0.43 .

\subsection{Hardness mapping}

Shown in Figure 9, hardness was mapped for the top, center, and bottom slices parallel to the substrate of the $125 \mathrm{~J} / \mathrm{mm}$ sample. The top slice (ninth layer) had an average hardness of $228 \pm$ $17 \mathrm{HV}$. Though large standard deviations lead to overlapping values, the hatching (235 $\pm 17 \mathrm{HV})$ was visibly harder than the contour $(225 \pm 16 \mathrm{HV})$. The center slice (fourth to fifth layer) had a higher average hardness than the top, with $263 \pm 21 \mathrm{HV}$. Again, the hardness values were higher in the hatching and lower in the contour, $274 \pm 24 \mathrm{HV}$ and $256 \pm 15$ respectively, a larger difference than in the top slice. In contrast, the bottom slice showed little difference in hardness between hatching (254 $\pm 11 \mathrm{HV})$ and contour $(246 \pm 12 \mathrm{HV})$. Average hardness for the bottom slice was $251 \pm 12 \mathrm{HV}$, softer than the center slice and harder than the top slice, but with less variation in values throughout the map. 
Cross sections perpendicular to the substrate of all samples were also examined by mapping hardness values from the contour of the left side through into the hatching, shown in Figure 10. Overall average hardness of the 125,75 , and $50 \mathrm{~J} / \mathrm{mm}$ samples were $251 \pm 13 \mathrm{HV}, 255 \pm 16 \mathrm{HV}$, and $281 \pm 14 \mathrm{HV}$, respectively. Each average was a result of a lower-hardness contour and a higher-hardness hatching. The $125 \mathrm{~J} / \mathrm{mm}$ did not include the overbuild, and it is inferred from the other samples that the average and contour hardness would decrease with the inclusion of the overbuild, as the overbuilt region had the lowest average hardness for both the $75 \mathrm{~J} / \mathrm{mm}$ and 50 $\mathrm{J} / \mathrm{mm}$ samples. For the $125 \mathrm{~J} / \mathrm{mm}$ cross section, the contour average hardness was $245 \pm 12 \mathrm{HV}$ and the hatching average hardness was $254 \pm 12 \mathrm{HV}$. The $75 \mathrm{~J} / \mathrm{mm}$ sample had contour average hardness $247 \pm 15 \mathrm{HV}$ and hatching average hardness of $263 \pm 14 \mathrm{HV}$. With the greatest difference between contour and hatching, the $50 \mathrm{~J} / \mathrm{mm}$ build had an average contour hardness of $272 \pm 12 \mathrm{HV}$ and hatching hardness of $290 \pm 10 \mathrm{HV}$.

Finally, hardness was mapped for the top face of the $75 \mathrm{~J} / \mathrm{mm}$ sample, shown in Figure 11 for comparison with the top slice of the $125 \mathrm{~J} / \mathrm{mm}$ build. Unlike the $125 \mathrm{~J} / \mathrm{mm}$ sample, the lower linear energy sample has its highest hardness within the contour, at the corner of the sample. Excepting this corner, the rest of the face followed a similar pattern; the rounded trace of the contour was slightly softer $(239 \pm 12 \mathrm{HV})$ than the top right corner, which was part of the hatching and averaged $244 \pm 16 \mathrm{HV}$. Overall, the $75 \mathrm{~J} / \mathrm{mm}$ sample face had a slightly higher average hardness of $241 \pm 14 \mathrm{HV}$, as compared to the $125 \mathrm{~J} / \mathrm{mm}$ top slice which had an average hardness of $228 \pm 17 \mathrm{HV}$.

\subsection{Laves and carbide distribution}

Backscatter imaging such as that in Figure 12 showed carbides and Laves phase brightly. Even at relatively low magnification (200x, Figure 4a), the edges of melt pools were visible due to a variation in the distribution of these bright phases. The alternate hypothesis for statistical analysis of the Laves distribution was that the Laves phase comprised a higher fraction of the 50$150 \mu \mathrm{m}$ at the melt pool boundary than the $50-150 \mu \mathrm{m}$ at the top section of the previous melt pool. Since the Laves and carbide phases could not be reliably distinguished in BEC micrographs, the hypothesis necessarily was revised to include carbides as well, though carbides were distributed evenly throughout the microstructure and have not impacted the difference evaluation. Calculated averages of area percent of Laves/carbides are shown in Table 2 along with the percent increase in the melt pool edge compared to the top of the previous melt pool, which ranged from 108-185\%. Using a null hypothesis that no difference existed, a difference of means t-test was conducted for each of six binarized images at 1300x at melt pool boundaries. There was a statistically significant difference between the area fraction of Laves/carbide phase in the melt pool edge and previous melt pool top, with $\alpha \ll 0.0005$ (typically $\alpha<0.05$ is considered statistically significant, and a lower value corresponds to increasing confidence in the conclusion). The average area percent of Laves/carbides in the melt pool edges analyzed was $3.58 \%$, the top of the previous melt pool was $1.46 \%$, and the overall average was $2.52 \%$. Note that since carbides are included in this calculation and are evenly distributed on both sides of the melt pool boundary, the relative difference in Laves phase area percentage is even more significant than reported here.

\section{Discussion}




\subsection{Elemental analysis}

With backscatter imaging shown in Figure 4, hatching and contour could be distinguished from each other, indicating a distinct segregation of elements. Upon closer examination, this macrosegregation was accompanied by a micro-segregation which defined a dendritic microstructure, as expected from DLD as a rapid solidification process [17, 25]. The dendrites had a dim core, which contained less $\mathrm{Nb}$ and Mo than the nominal composition (Figure 3). Surrounding the core was a light $\gamma^{\prime \prime}$-containing region, which contained an increase in $\mathrm{Nb}$ and Mo similar to that found in the needle-shaped $\delta$ particles. This similarity is expected, since both phases have approximately $\mathrm{Ni}_{3} \mathrm{Nb}$ composition. Contained within the light region were bright eutectic products that were rich in $\mathrm{Nb}$ and Mo. This distribution of elements suggested that the nonequilibrium rapid solidification that occurs during the DLD process carried the heavier elements of $\mathrm{Nb}$ and Mo with the solid-liquid interface of the subgrain structures. These regions are likely precursors to the $\gamma^{\prime \prime}$ phase, which consists of $\mathrm{Ni}_{3} \mathrm{Nb}$, and is the strengthening phase in alloy 718 . Though the $\gamma^{\prime \prime}$ phase is nano-sized, a conglomeration of particles could still appear as a bright region in backscatter imaging. This analysis is supported by the work of Tian et al. [27]. The Nband Mo- enriched region also allowed for the formation of $\mathrm{NbC}$ carbides and the detrimental Laves phase, both of which have been found to form at subgrain boundaries of DLD- and DLFdeposited alloy 718 [25, 27, 30]. It is suggested by Ma et al [25] that increasing energy during deposition (in this case, increasing linear energy) leads to increased Laves phase formation, though no such effect was seen in this study, potentially a result of low disparity between processing parameters. There was also no observed difference in density or distribution of the Laves phase throughout the cross-sectional height, though the highly variable microstructure makes a systematic comparison difficult. However, an increased amount of the Laves phase was seen at the edges of melt pools and scan lines, leading to the visibility of scan lines in Figure 4.

\subsection{Grain structure}

Little change in orientation was seen across boundaries on the top faces of both the $125 \mathrm{~J} / \mathrm{mm}$ and $75 \mathrm{~J} / \mathrm{mm}$ samples in Figure 9 and Figure 11. This is due to remelting: the solidified regions provide nucleation sites, so grains grow in the same orientation across region boundaries. No difference was observed due to processing parameters, therefore variation in grain size and morphology is unlikely to have effected the observed hardness anisotropy within samples. It is noted however, that the area scanned was on the order of a single melt pool, and a larger area may need to be examined. On the face of the $75 \mathrm{~J} / \mathrm{mm}$ sample (Figure 11), a circular area of smaller grains, radiating from the bottom left corner of the image, is likely the final position of the laser for that layer. No further remelting would have occurred at that location within the layer, and it appears that the next layer did not remelt far enough into the current layer to change the grains in this location. When the laser turns off, the final melt pool solidifies from the nucleation sites in the layer beneath, and grains grow towards the center of the melt pool, the final material to solidify. With a view of the top face, the build-height-parallel elongation is not visible and the grains appear to be small and angled towards the center of what was the final melt pool.

Cross-sectional EBSD in Figure 7 showed different grain morphologies between the 125 and 50 $\mathrm{J} / \mathrm{mm}$ samples. Data for the $125 \mathrm{~J} / \mathrm{mm}$ sample was collected over half the build height, and when aligned with the etched cross-sectional micrograph, revealed the solidification behavior and its effect on grain growth. Where remelting occurred, grain orientation was maintained into a new 
melt pool due to nucleation from the previously-solidified layer or hatch line. Shown in Figure 13, grains along the edges of each melt pool were columnar towards the center, which had smaller, more equiaxed grains. Such a structure has been established in weldments [35], knowledge which can be combined with the computationally predicted maximum temperature gradients for a multi-layer DLD alloy 718 [36]. Within the fusion zone (FZ) of a welding melt pool, solidification has been modelled and studied for many years [37]. Solidification microstructure is linked to a ratio of thermal gradient at the solid-liquid interface $(G)$ and interface velocity $(R)[38,39]$. A plot of $G$ vs. $R$ showing the solidification path of a melt pool, and a schematic of grain growth based on isotherm location is shown in Figure 14. Grain growth is initially columnar, elongated towards the solidification front, approximately perpendicular to isotherms (aligned with the greatest thermal gradient). Within the approximate center of the melt pool, thermal gradient $G$ decreases and cooling rate $R$ increases: a small volume of liquid is in contact both with the atmosphere and already-solidified material. These conditions favor nucleation over growth and the resulting grain structure for the melt pool approximate center is equiaxed. The results of this study support the correlation between weldment structures and isolated sections of DLD-manufactured parts, while referring to computational data on maximum thermal gradients for 3D DLD alloy 718 samples.

\subsection{Hardness distribution}

Mapping of hardness values showed a difference in hardness between the contour and the hatching (Figures 7-9). It has been reported that the structure and properties of a sample are anisotropic throughout a DLD-printed part [14, 40-42], and the results from this study support that finding and add more detail.

Hardness in the contour was consistently less than that of the hatching, for all samples. This may be caused by a variation in the distribution of the detrimental Laves phase, which has been found to form during final solidification according to $\mathrm{L} \rightarrow \gamma+$ Laves. This would imply that the greatest amount of Laves phase would be found at the location of final solidification, i.e. the center of the melt pool. However, it is suggested that the Laves phase spontaneously decomposes into an (Al, $\mathrm{Ti}, \mathrm{Nb}$ )-rich phase [33]. This phase, upon remelting, appears to allow for increased Laves phase at the edges of the new melt pool, as seen in Figure 12 and supported by statistical analysis. This Laves phase depletes the $\mathrm{Nb}$ available to form the strengthening phase $\gamma^{\prime \prime}$.

Since remelting of the contour is more frequent for the process parameters used (increased overlapping melt pools from the single-bead contour and multi-bead hatching), there are many melt pool edges in the contour. This is in contrast with the hatching, where melt pool and scan line edges occur systematically with each scan line. This increase in overlap and non-uniform melt pool edge location in the contour can be seen in Figure 13 where the contour is the rightmost $\sim 700 \mu \mathrm{m}$ in the large micrograph, and the rest of the image to the left is hatching. Less overlap and consistently spaced melt pool edges in the hatching led to a lesser amount of highdensity Laves phase area, which may be the cause of the higher hatching hardness.

Hardness mapping for both the cross sections and the sample faces showed an increase in hardness with decreasing linear energy, a result comparable to that found for a thin-walled structure [25]. The results of this study confirm that the same is true for 3D cuboidal parts, with the proposed reasoning being that an increase in input energy increases the amount of Laves 
phase and decreases the $\mathrm{Nb}$ available for $\gamma^{\prime \prime}$ formation [25, 27]. There is also a hardness difference between the slices of the $125 \mathrm{~J} / \mathrm{mm}$ sample: much lower hardness in the top slice than either the center or bottom slices (Figure 9). This decrease in hardness with height is supported by experiments by Zheng et al on 316L stainless steel samples [40]. This hardness difference with height may be caused by a difference in strengthening phase concentration, in agreement with analysis by Tian et al. for a thin-walled cladding structure [27]. In alloy 718, $\gamma^{\prime \prime}$ is not expected to form during initial rapid solidification but rather to develop during subsequent heating cycles. Therefore, the lower hardness on the top slice may be due in to a decrease in strengthening phase. In addition, there may be an elemental segregation discrepancy: at the bottom, the substrate is cool, causing the deposited material to cool too quickly for as much segregation to occur. Less segregation causes less available $\mathrm{Nb}$ to form the strengthening $\gamma^{\prime \prime}$ In the center, there is a lower cooling rate, more segregation, and more available $\mathrm{Nb}$ to later form $\gamma^{\prime \prime}$. At the top, the laser only travels over the area once, leading to a lower amount of segregation since there are no subsequent heat treatments.

\section{Conclusions}

Effects of microstructure and processing parameters on the hardness of DLD-deposited alloy 718 parts was examined. Elemental analysis showed micro-segregation (dendrites and cells) and macro-segregation (scan lines) present in the samples. EBSD analysis revealed coarse, columnar grains that maintained their orientation across the hatching-contour boundary and sometimes across layer boundaries. Single melt pools solidified with columnar grains growing from the edge of the melt pool towards the center, then with equiaxed grains in the center. Three trends in hardness were found: a decrease in hardness for the contour over the hatching, a decrease in hardness with increasing linear energy, and a variation in hardness over height for slices parallel to the substrate. All trends can be rationalized by the distribution of the $\gamma^{\prime \prime}$ strengthening phase. Due to (1) increased Laves phase formation caused by an increased number of melt pool boundaries in the contour, (2) an increase in linear energy, and (3) a variation in elemental segregation and reheating, less $\gamma^{\prime \prime}$ is formed (1) in the contour, (2) at higher linear energies, and (3) at the top. Laves/carbide phase area percent average was found to be $2.52 \%$, while the top of the previously-deposited melt pool was $3.58 \%$ and the melt pool edge was $1.46 \%$.

\section{Acknowledgements}

The authors would like to acknowledge the contributions of Meredith Meyer, Eamonn Hughes, and Colleen Hilla to data collection and Amir Mostafaei to manuscript preparation. Partial funding was provided by the National Science Foundation (CMMI-1434077), Swanson School of Engineering, and the Office of the Provost of the University of Pittsburgh. The authors also appreciate David Dunand (Department of Materials Science and Engineering, Northwestern University), Matthew Olszta, Nicole Overman (Reactor Materials \& Mechanical Design Group, Pacific Northwest National Laboratory), Anthony Rollett (Carnegie Mellon University), Joshua Selling and Christopher Dumm (University of Pittsburgh) for discussions. 


\section{References}

1. S. Mellor, L. Hao, and D. Zhang, Additive manufacturing: A framework for implementation. International Journal of Production Economics, 2014. 149: p. 194-201 DOI: 10.1016/j.ijpe.2013.07.008.

2. S. Ford and M. Despeisse, Additive manufacturing and sustainability: an exploratory study of the advantages and challenges. Journal of Cleaner Production, 2016 DOI: 10.1016/j.jclepro.2016.04.150.

3. I. Gibson, D.W. Rosen, and B. Stucker, Development of Additive Manufacturing Technology, in Additive Manufacturing Technologies. 2010, Springer US. p. 17-39.

4. W.E. Frazier, Metal Additive Manufacturing: A Review. Journal of Materials Engineering and Performance, 2014. 23(6): p. 1917-1928 DOI: 10.1007/s11665-014-0958-z.

5. I. Palčič, M. Balažic, M. Milfelner, and B. Buchmeister, Potential of Laser Engineered Net Shaping (LENS) Technology. Mater. Manuf. Process, 2009. 24: p. 750-753 DOI: 10.1080/10426910902809776.

6. J.D. Majumdar and I. Manna, Introduction to Laser Assisted Fabrication of Materials. 2013. 161: p. 1-67 DOI: 10.1007/978-3-642-28359-8_1.

7. R. Grylls, Intricate parts from the inside out. Machine Design, 2003. 75(17): p. 56-62.

8. S. Cheruvathur, E.A. Lass, and C.E. Campbell, Additive Manufacturing of 17-4 PH Stainless Steel: Post-processing Heat Treatment to Achieve Uniform Reproducible Microstructure. Jom, 2015. 68(3): p. 930-942 DOI: 10.1007/s11837-015-1754-4.

9. B. Vrancken, L. Thijs, J.-P. Kruth, and J. Van Humbeeck, Heat treatment of Ti6Al4V produced by Selective Laser Melting: Microstructure and mechanical properties. Journal of Alloys and Compounds, 2012. 541: p. 177-185 DOI: 10.1016/j.jallcom.2012.07.022.

10. B. Baufeld, O.V.d. Biest, and R. Gault, Additive manufacturing of Ti-6Al-4V components by shaped metal deposition: Microstructure and mechanical properties. Materials \& Design, 2010. 31: p. S106-S111 DOI: 10.1016/j.matdes.2009.11.032.

11. A. Mostafaei, E.L. Stevens, E.T. Hughes, S.D. Biery, C. Hilla, and M. Chmielus, Powder bed binder jet printed alloy 625L Densification, microstructure and mechanical properties. Materials and Design, 2016. 108: p. 126-135 DOI: 10.1016/j.matdes.2016.06.067.

12. A. Mostafaei, Y. Behnamian, Y.L. Krimer, E.L. Stevens, J.L. Luo, and M. Chmielus, Effect of solutionizing and aging on the microstructure and mechanical properties of power bed binder jet printed nickel-based superalloy 625. Materials and Design, 2016. 111: p. 482-491 DOI: 10.1016/j.matdes.2016.08.083.

13. A. Mostafaei, J. Toman, E.L. Stevens, E.T. Hughes, Y.L. Krimer, and M. Chmielus, Microstructural evolution and mechanical properties of differently heat-treated binder jet printed samples from gas- and water-atomized alloy 625 powders. Acta Materialia, 2016 DOI: 10.1016/j.actamat.2016.11.021.

14. V.D. Manvatkar, A.A. Gokhale, G.J. Reddy, A. Venkataramana, and A. De, Estimation of Melt Pool Dimensions, Thermal Cycle, and Hardness Distribution in the Laser-Engineered Net Shaping Process of Austenitic Stainless Steel. Metallurgical and Materials Transactions, 2011. 42(13): p. 4080-4087 DOI: 10.1007/s11661-011-0787-8.

15. B. Zheng, Y. Zhou, J.E. Smugeresky, J.M. Schoenung, and E.J. Lavernia, Thermal Behavior and Microstructural Evolution during Laser Deposition with Laser-Engineered Net Shaping: Part I. Numerical Calculations. Metallurgical and Materials Transactions A, 2008. 39(9): p. 2228-2236 DOI: 10.1007/s11661-008-9557-7. 
16. L. Bian, S.M. Thompson, and N. Shamsaei, Mechanical Properties and Microstructural Features of Direct Laser-Deposited Ti-6Al-4V. Jom, 2015. 67(3): p. 629-638 DOI: 10.1007/s11837-0151308-9.

17. N. Shamsaei, A. Yadollahi, L. Bian, and S.M. Thompson, An overview of Direct Laser Deposition for additive manufacturing; Part II: Mechanical behavior, process parameter optimization and control. Additive Manufacturing, 2015. 8: p. 12-35 DOI: 10.1016/j.addma.2015.07.002.

18. M. Gaumann, S. Henry, F. Cleton, J.-D. Wagniere, and W. Kurz, Epitaxial laser metal forming: analysis of microstructure formation. Materials Science and Engineering, 1999. A271: p. 232241.

19. W. Kurz, C. Bezencon, and M. Gaumann, Columnar to equiaxed transition in solidification processing. Science nad Technology of Advanced Materials, 2001. 2(1): p. 185-191.

20. R.C. Reed, Introduction, in Superalloys - Fundamentals and Applications. 2006, Cambridge University Press. p. 1-32.

21. F.C. Campbell, Superalloys, in Manufacturing Technology for Aerospace Structural Materials. 2006, Elsevier.

22. R.C. Reed and C.M.F. Rae, Physical Metallurgy of the Nickel-Based Superalloys. 2014: p. 22152290 DOI: 10.1016/b978-0-444-53770-6.00022-8.

23. R.C. Reed, The Physical Metallurgy of Nickel and its Alloys, in Superalloys - Fundamentals and Applications. 2006, Cambridge University Press. p. 33-120.

24. H. Qi, M. Azer, and A. Ritter, Studies of Standard Heat Treatment Effects on Microstructure and Mechanical Properties of Laser Net Shape Manufactured INCONEL 718. Metallurgical and Materials Transactions A, 2009. 40(10): p. 2410-2422 DOI: 10.1007/s11661-009-9949-3.

25. M. Ma, Z. Wang, and X. Zeng, Effect of energy input on microstructural evolution of direct laser fabricated IN718 alloy. Materials Characterization, 2015. 106: p. 420-427 DOI: 10.1016/j.matchar.2015.06.027.

26. Q. Jia and D. Gu, Selective laser melting additive manufacturing of Inconel 718 superalloy parts: Densification, microstructure and properties. Journal of Alloys and Compounds, 2014. 585: p. 713-721 DOI: 10.1016/j.jallcom.2013.09.171.

27. Y. Tian, D. McAllister, H. Colijn, M. Mills, D. Farson, M. Nordin, and S. Babu, Rationalization of Microstructure Heterogeneity in INCONEL 718 Builds Made by the Direct Laser Additive Manufacturing Process. Metallurgical and Materials Transactions A, 2014. 45(10): p. 4470-4483 DOI: 10.1007/s11661-014-2370-6.

28. K.N. Amato, S.M. Gaytan, L.E. Murr, E. Martinez, P.W. Shindo, J. Hernandez, S. Collins, and F. Medina, Microstructures and mechanical behavior of Inconel 718 fabricated by selective laser melting. Acta Materialia, 2012. 60(5): p. 2229-2239 DOI: 10.1016/j.actamat.2011.12.032.

29. M.T. Jovanovic, Z. Miskovic, and B. Lukic, Microstructure and stress-rupture life of polycrystal, directionally solidified, and single crystal castings of nickel-based IN 939 superalloy. Materials Characterization, 1998. 40: p. 261-268.

30. L.L. Parimi, R.G. A, D. Clark, and M.M. Attallah, Microstructural and texture development in direct laser fabricated IN718. Materials Characterization, 2014. 89: p. 102-111 DOI: 10.1016/j.matchar.2013.12.012.

31. C.A. Schneider, W.S. Rasband, and K.W. Eliceiri, NIH Image to ImageJ: 25 years of Image analysis. Nature methods, 2012. 9(7): p. 671-675.

32. K. Kulawik, P.A. Buffat, A. Kruk, A.M. Wusatowska-Sarnek, and A. Czyrska-Filemonowicz, Imaging and characterization of $\gamma^{\prime}$ and $\gamma^{\prime \prime}$ nanoparticles in Inconel 718 by EDX elemental mapping and FIB-SEM tomography. Materials Characterization, 2015. 100: p. 74-80 DOI:

10.1016/j.matchar.2014.12.012. 
33. Y. Zhang, Z. Li, P. Nie, and Y. Wu, Effect of Cooling Rate on the Microstructure of Laser-Remelted INCONEL 718 Coating. Metallurgical and Materials Transactions A, 2013. 44(12): p. 5513-5521 DOI: 10.1007/s11661-013-1903-8.

34. R.G. Ding, Z.W. Huang, H.Y. Li, I. Mitchell, G. Baxter, and P. Bowen, Electron microscopy study of direct laser deposited IN718. Materials Characterization, 2015. 106: p. 324-337 DOI: 10.1016/j.matchar.2015.06.017.

35. Weld Solidification, in Weld Integrity and Performance. 1997, ASM International. p. 3-12.

36. H.L. Wei, J. Mazumder, and T. DebRoy, Evolution of solidification texture during additive manufacturing. Sci Rep, 2015. 5: p. 16446 DOI: 10.1038/srep16446.

37. S.A. David, S.S. Babu, and J.M. Vitek, Welding: Solidification and Microstructure. Journal of Materials, 2003: p. 14-20.

38. J.C. Lippold, Welding Metallurgy Principles, in Welding Metallurgy and Weldability. 2015, John Wiley \& Sons. p. 9-83.

39. N. Raghavan, R. Dehoff, S. Pannala, S. Simunovic, M. Kirka, J. Turner, N. Carlson, and S.S. Babu, Numerical modeling of heat-transfer and the influence of process parameters on tailoring the grain morphology of IN718 in electron beam additive manufacturing. Acta Materialia, 2016. 112: p. 303-314 DOI: 10.1016/j.actamat.2016.03.063.

40. B. Zheng, Y. Zhou, J.E. Smugeresky, J.M. Schoenung, and E.J. Lavernia, Thermal Behavior and Microstructure Evolution during Laser Deposition with Laser-Engineered Net Shaping: Part II. Experimental Investigation and Discussion. Metallurgical and Materials Transactions A, 2008. 39(9): p. 2237-2245 DOI: 10.1007/s11661-008-9566-6.

41. T. Durejko, M. Ziętala, M. Łazińska, S. Lipiński, W. Polkowski, T. Czujko, and R.A. Varin, Structure and properties of the Fe3Al-type intermetallic alloy fabricated by laser engineered net shaping (LENS). Materials Science and Engineering: A, 2016. 650: p. 374-381 DOI: 10.1016/j.msea.2015.10.076.

42. A. Yadollahi, N. Shamsaei, S.M. Thompson, and D.W. Seely, Effects of process time interval and heat treatment on the mechanical and microstructural properties of direct laser deposited $316 \mathrm{~L}$ stainless steel. Materials Science and Engineering: A, 2015. 644: p. 171-183 DOI: 10.1016/j.msea.2015.07.056.

43. J. Gockel, N. Klingbeil, and S. Bontha, A Closed-Form Solution for the Effect of Free Edges on Melt Pool Geometry and Solidification Microstructure in Additive Manufacturing of Thin-Wall Geometries. Metallurgical and Materials Transactions B, 2015. 47(2): p. 1400-1408 DOI: 10.1007/s11663-015-0547-z.

\section{Tables}

Table 1. Composition (in wt.-\%) of regions of phases in DLD-printed alloy 718, analyzed with EDS. "Note that carbon is excluded from results due to EDS limitations and contamination causing false results, but carbides were initially identified with linescans.

\begin{tabular}{|l|l|l|l|l|l|l|l|l|l|l|l|l|l|}
\hline & $\mathbf{N i}$ & $\mathbf{N b}$ & $\mathbf{M o}$ & $\mathbf{F e}$ & $\mathbf{A l}$ & $\mathbf{T i}$ & $\mathbf{C r}$ & $\mathbf{C u}$ & $\mathbf{T a}$ & $\mathbf{C o}$ & $\mathbf{S i}$ & $\mathbf{P}$ & $\mathbf{S}$ \\
\hline Laves & 42.8 & 23.5 & 4.4 & 12.9 & 0.4 & 1.8 & 13.9 & 1.9 & 0.1 & 0.1 & 0.1 & 0.0 & 0.1 \\
\hline$\delta$ & 44.3 & 15.9 & 4.2 & 14.1 & 0.4 & 1.7 & 16.4 & 1.9 & 0.0 & 0.1 & 0.1 & 0.0 & 0.1 \\
\hline Matrix $(\gamma)$ & 50.7 & 2.9 & 2.8 & 19.7 & 0.6 & 0.9 & 19.2 & 2.6 & 0.0 & 0.0 & 0.1 & 0.0 & 0.1 \\
\hline${ }^{\prime \prime}$ region & 49.0 & 10.2 & 3.5 & 15.7 & 0.5 & 1.9 & 17.0 & 1.9 & 0.3 & 0.1 & 0.0 & 0.0 & 0.0 \\
\hline Carbide $^{*}$ & 20.6 & 51.3 & 3.6 & 8.1 & 0.3 & 4.9 & 9.9 & 1.0 & 0.0 & 0.1 & 0.1 & 0.0 & 0.0 \\
\hline
\end{tabular}


Table 2. Area percent analysis and percent increase in the melt pool edge of Laves and carbide phases, with carbides being evenly distributed. "Top" refers to the top 50-150 $\mu \mathrm{m}$ of the previously-solidified melt pool. "Edge" refers to the bottom $50-150 \mu \mathrm{m}$ of the subsequently-built melt pool edge.

\begin{tabular}{|c|c|c|c|}
\hline \multirow{2}{*}{ Image } & Region & $\begin{array}{c}\text { Average Area } \\
\%\end{array}$ & \% Increase \\
\hline \multirow{2}{*}{1} & Top & 1.35 & \\
\cline { 2 - 4 } & Edge & 3.83 & 185 \\
\hline \multirow{2}{*}{2} & Top & 1.59 & \\
\cline { 2 - 4 } & Edge & 3.86 & 143 \\
\hline \multirow{2}{*}{3} & Top & 1.89 & \\
\cline { 2 - 4 } & Edge & 4.33 & 128 \\
\hline \multirow{2}{*}{4} & Top & 1.52 & \\
\cline { 2 - 4 } & Edge & 3.17 & 108 \\
\hline \multirow{2}{*}{5} & Top & 1.45 & \multicolumn{1}{|c|}{} \\
\cline { 2 - 4 } & Edge & 3.89 & 168 \\
\hline \multirow{2}{*}{6} & Top & 0.95 & 157 \\
\cline { 2 - 4 } & Edge & 2.43 & \multicolumn{2}{|c|}{} \\
\hline
\end{tabular}




\section{Figure Captions}

Figure 1. Schematic of build process and terminology.

Figure 2. Exemplary build: (a) tilted as-built sample and (b) etched cross-section.

Figure 3. Representative EDS area scan results of microsegregation on the cross-section of the $75 \mathrm{~J} / \mathrm{mm}$ sample, at (a) higher and (b) lower magnifications. Nb and Mo segregation is shown, being most prominent.

Figure 4. (a) Low magnification BEC micrograph showing contrast between melt pool lines. (b) Distinction of the edge of a single melt pool line. (c) Representative high-magnification image of an area with varying contrast analyzed with EDS. (d) Phases identified throughout the samples: eutectic Laves phase, approximately spherical NbC carbides, and light $\gamma^{\prime \prime}$-containing regions. All micrographs were taken from the $125 \mathrm{~J} / \mathrm{mm}$ sample, but are representative of all samples.

Figure 5. (a) High resolution secondary electron image of the Laves phase and accompanying carbide and $\delta$ phases, identified by comparison to Parimi et al. [30] (b) Through-the-lens (TLD) micrograph of alloy 718, showing Laves phase and carbides in white, and a diffuse light region identified as $\gamma^{\prime \prime}$-containing via Tian et al. [27]

Figure 6. EBSD micrographs at the contour-hatching interface of the two highest linear energy samples.

Figure 7. $125 \mathrm{~J} / \mathrm{mm}$ sample cross section, etched, with overlay of EBSD micrograph and visible edges of melt pools traced (left). $50 \mathrm{~J} / \mathrm{mm}$ sample cross section EBSD data (right). Sections used for grain size and aspect ratio analysis are indicated in both orientation maps. The red box in the schematic at the bottom right represents the location of the maps on the sample face, with the green line representing the edge of the contour and the solid black line representing the edge of the sample.

Figure 8. Plots showing the grain size (red circles) and aspect ratio (black squares) evolution over height, calculated from EBSD data.

Figure 9. Hardness maps for the top, center, and bottom slices of $125 \mathrm{~J} / \mathrm{mm}$ sample. Scale is the same for all three hardness maps. Testing area was approximately a quarter of the sample face, as shown in the schematic on the bottom right.

Figure 10. Hardness maps for sample cross sections. Note that the $125 \mathrm{~J} / \mathrm{mm}$ map does not include the overbuild which, if included, would presumably lower the average hardness.

Figure 11. Hardness mapping for the top face of the $75 \mathrm{~J} / \mathrm{mm}$ sample, for comparison to the top slice of the $125 \mathrm{~J} / \mathrm{mm}$ build, in Figure 9. 
Figure 12. Laves/carbide phase distribution mapping process for two representative melt pool boundary areas. (a) Backscattered SEM micrographs at 1300x of melt pool boundaries, showing Laves phase and carbides as white. (b) Binarized ImageJ-generated images, showing only Laves/carbide phases in black. (c) Mapping of Laves/carbide phase area percentage, where higher area percent is shown in black.

Figure 13. EBSD overlay on etched $125 \mathrm{~J} / \mathrm{mm}$ cross section, with an enlarged view of a melt pool that exhibited columnar growth near the bottom of the melt pool and smaller, more equiaxed grains at the top.

Figure 14. Plot of the effect of temperature gradient $G$ and solidification rate $R$ on grain morphology within a solidifying melt pool. Indicated solidification path is based on simulation work in [39] for electron beam melting of alloy 718. The inset is a schematic of cross-sectional grain growth within a single melt pool, at the end of a hatching scan line. Approximate isotherms during solidification are shown in (a), and resulting microstructure is shown in (b). Columnar grains grow from the edge of the melt pool towards center of the melt pool, then final solidification is equiaxed grains. Isotherm data is adapted from [36, 43]. 


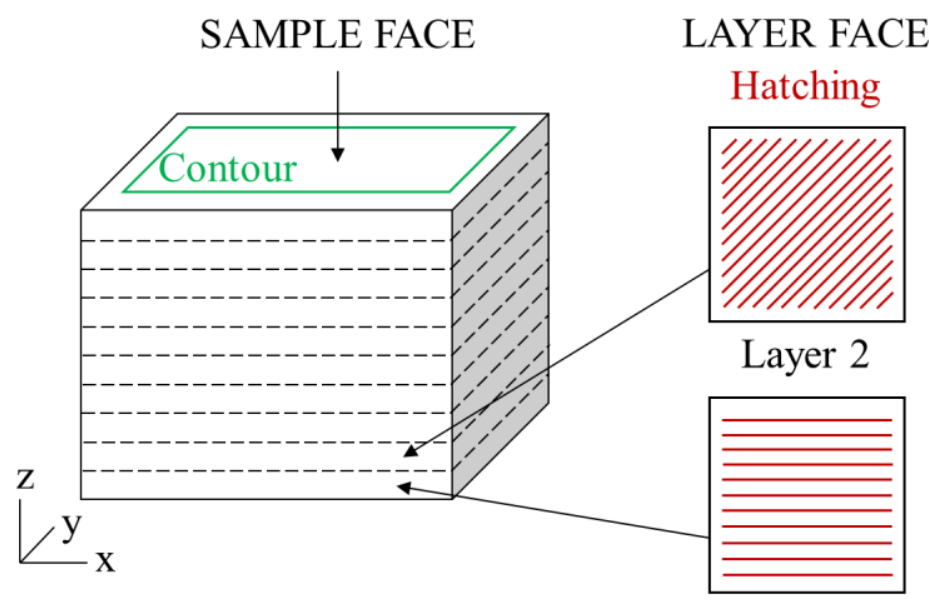

Layer 1 

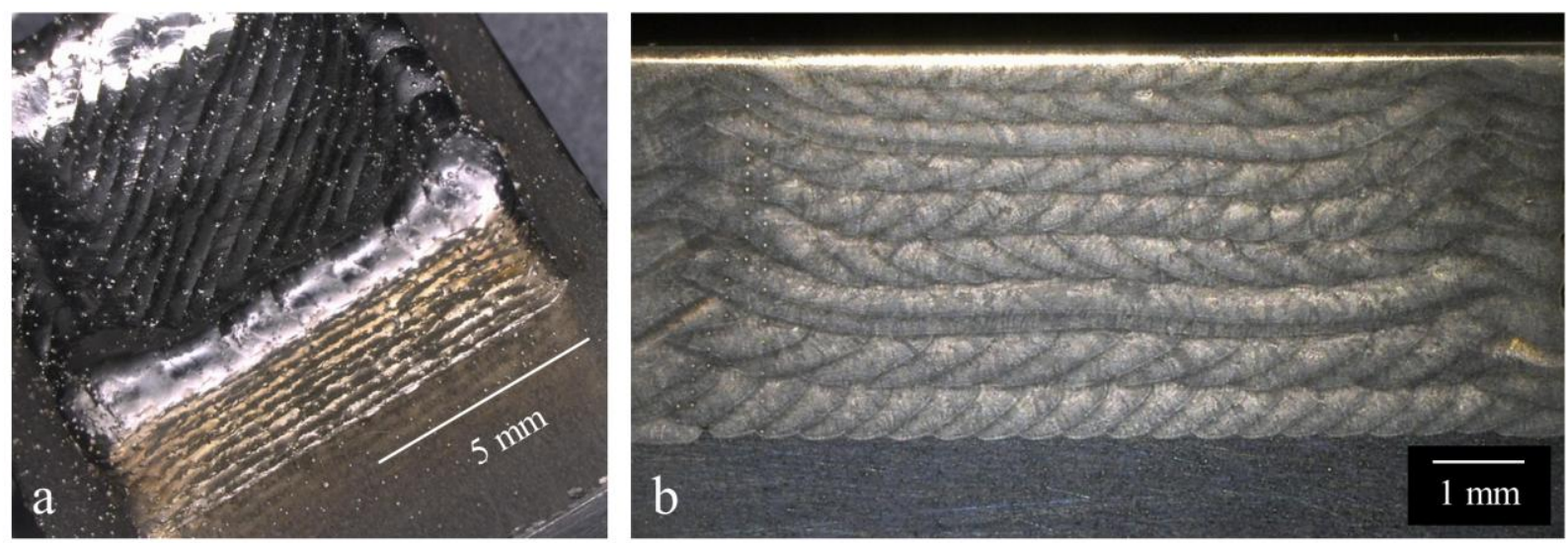

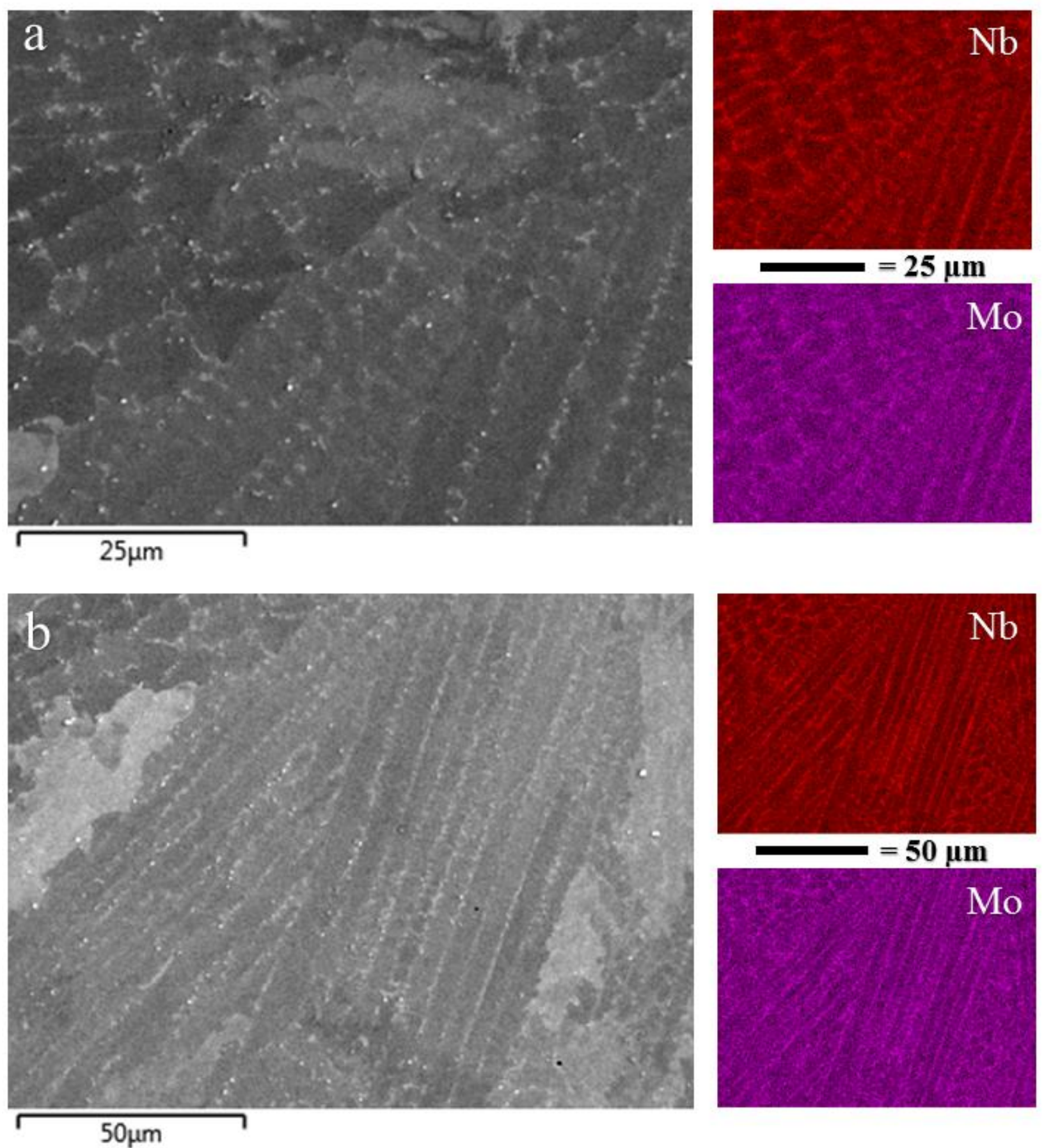


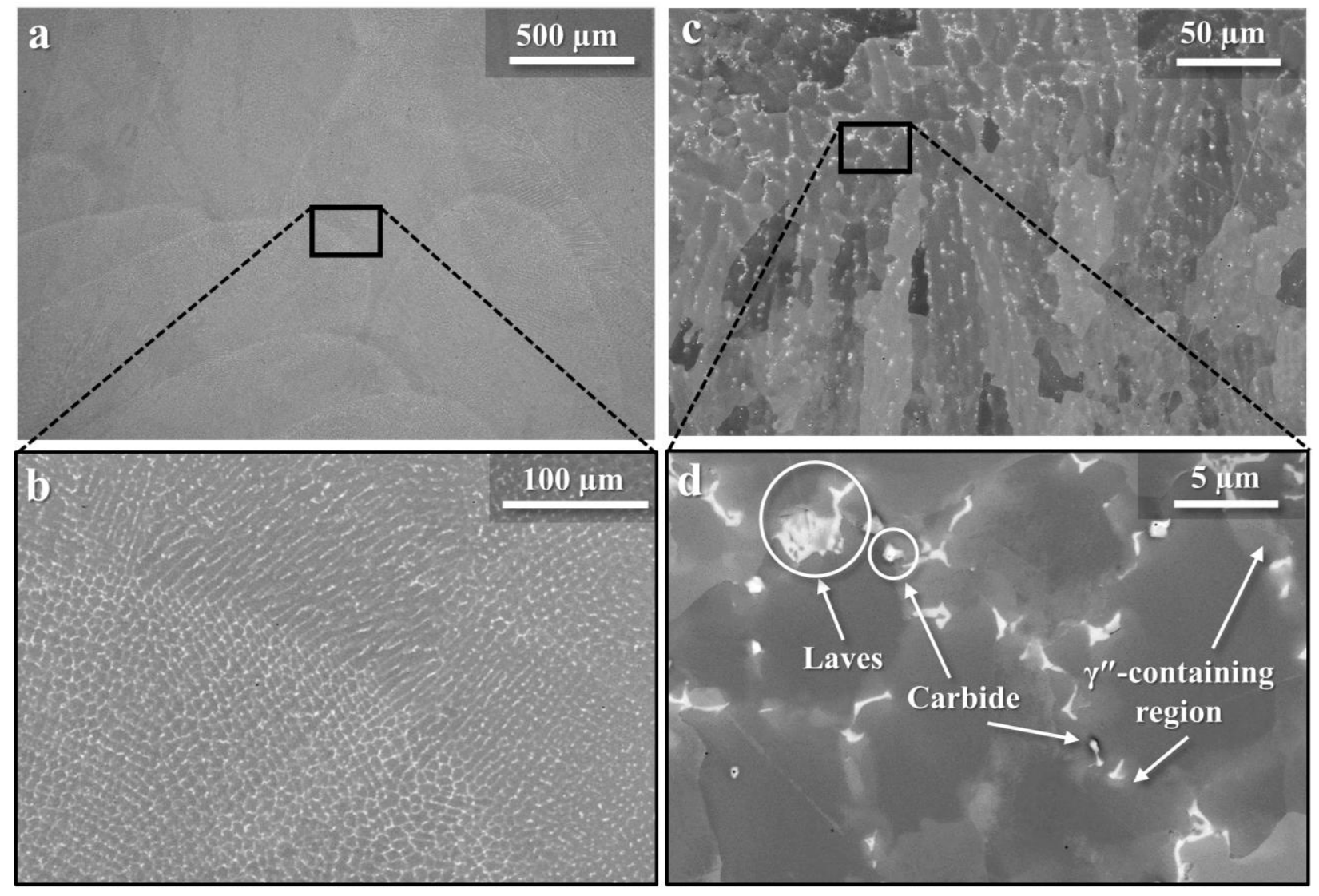




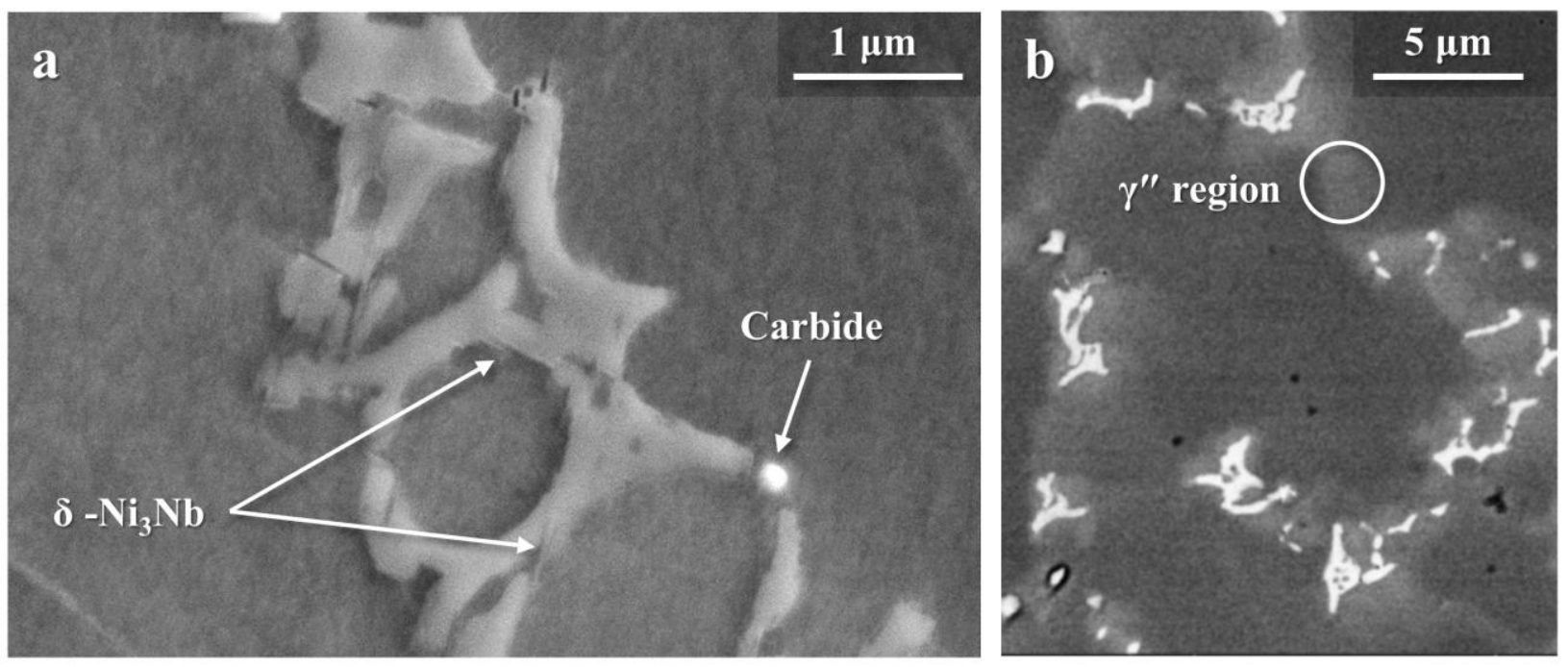



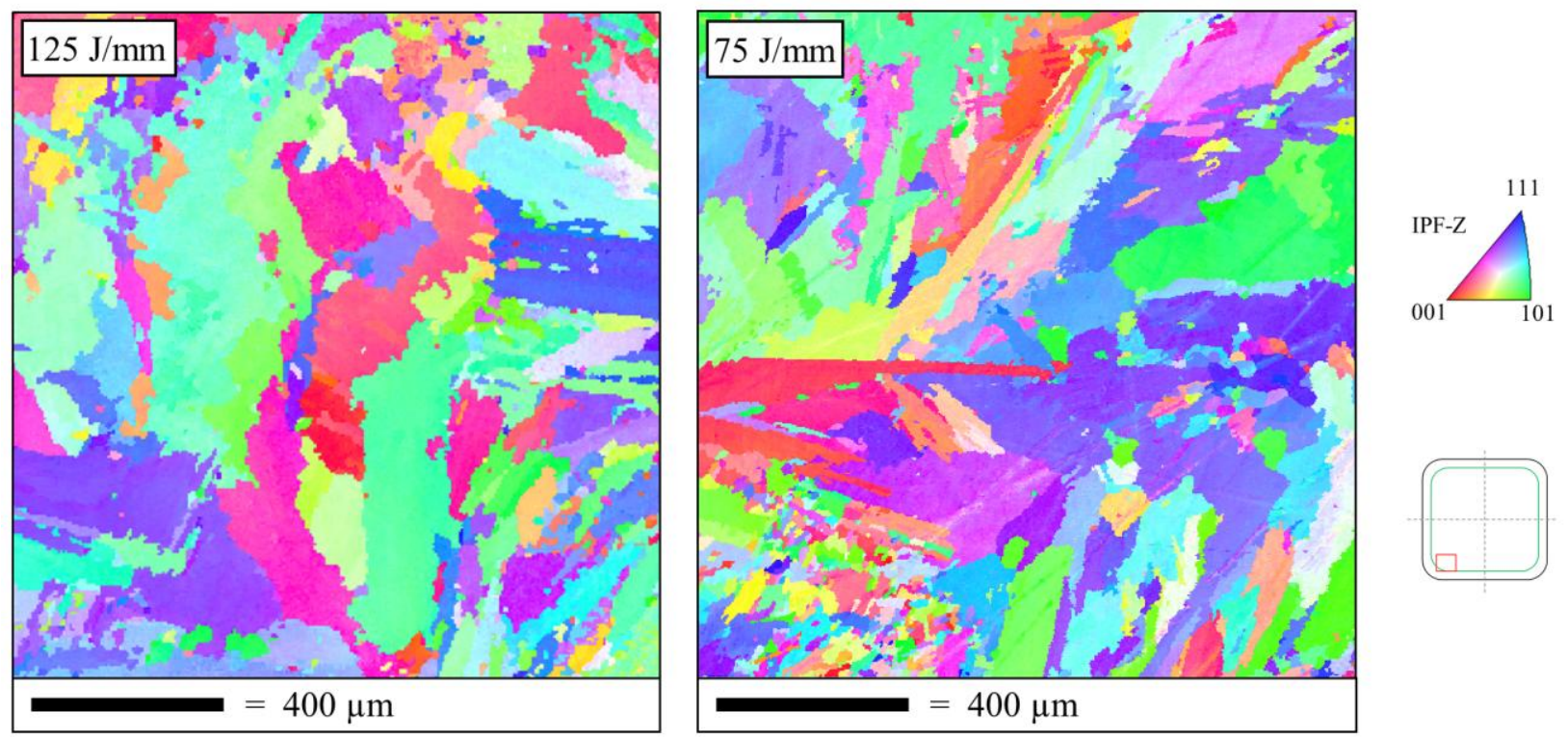


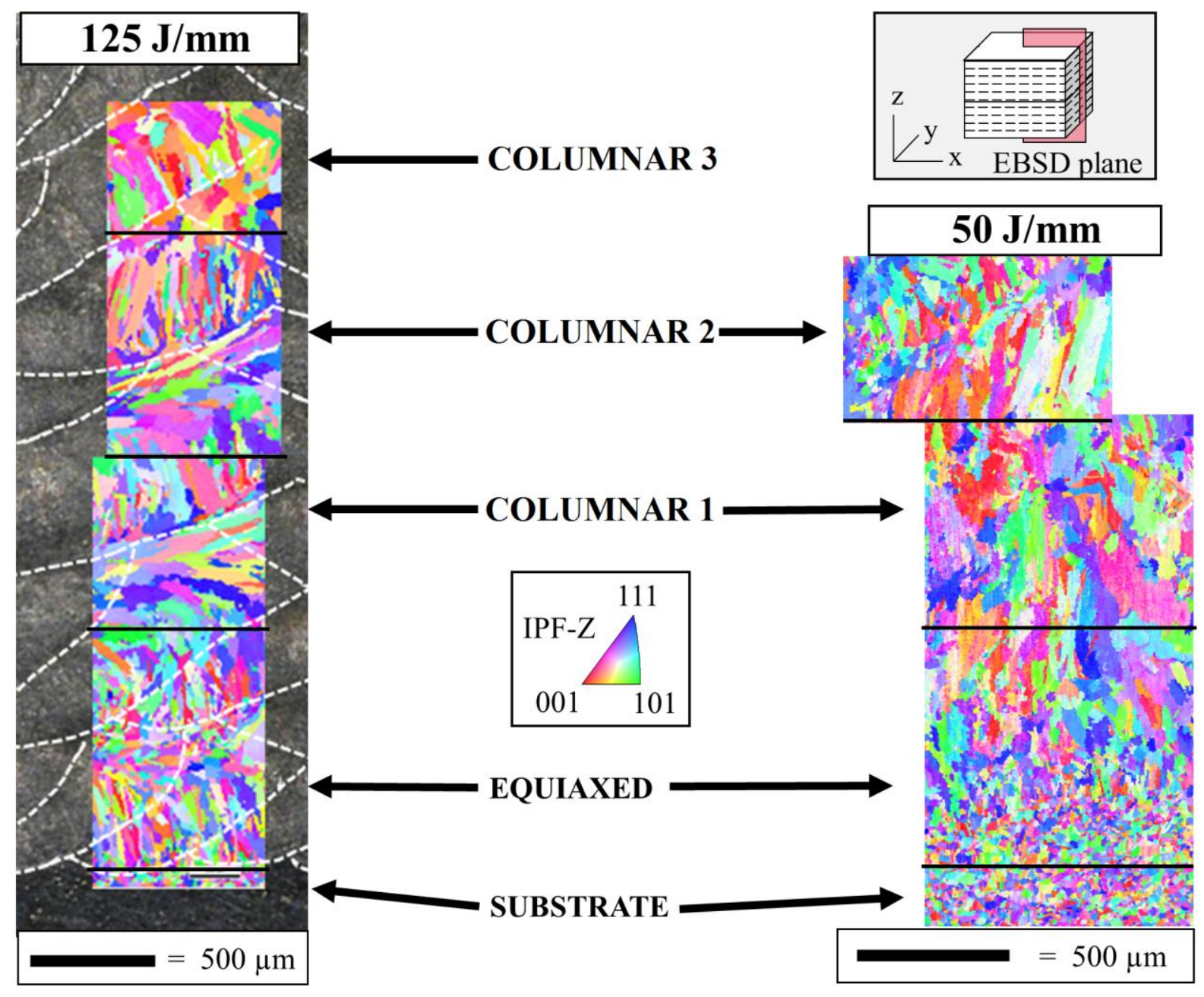


Region

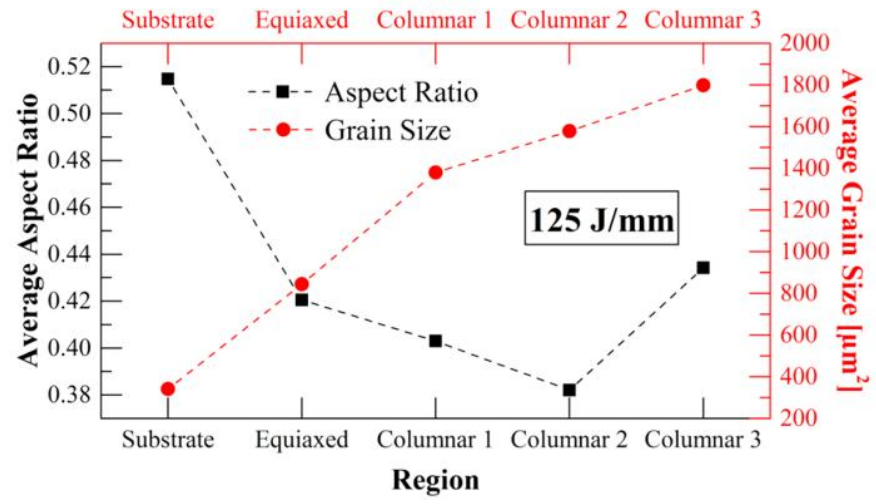

Region

Substrate Equiaxed Columnar 1 Columnar 2

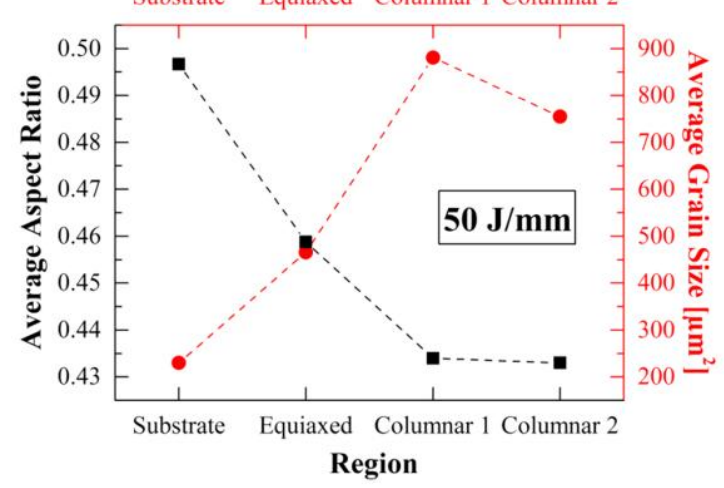




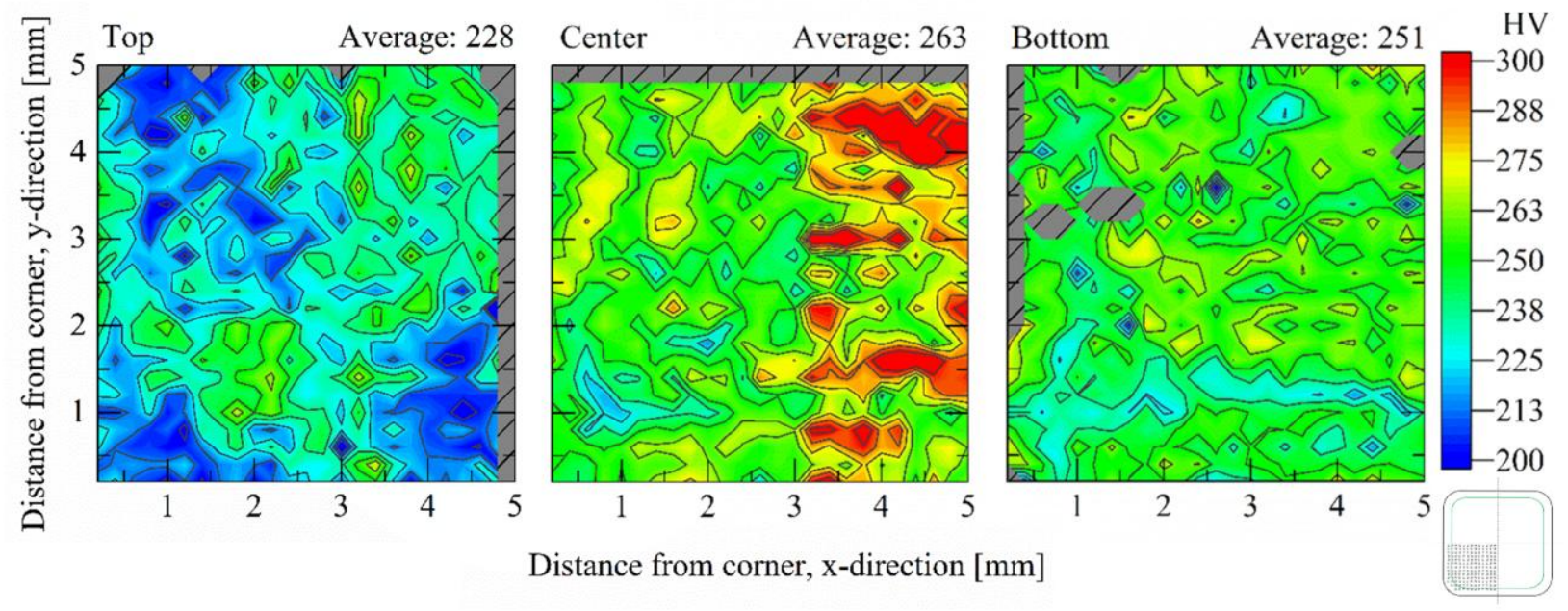




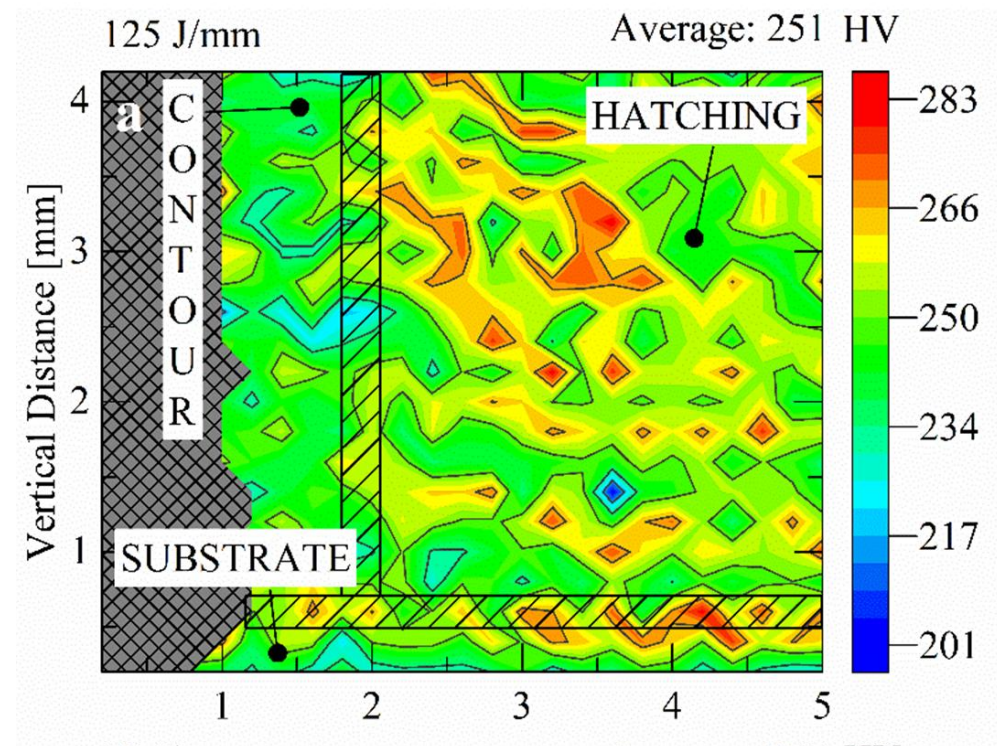

$75 \mathrm{~J} / \mathrm{mm} \quad$ Average: $255 \mathrm{HV}$
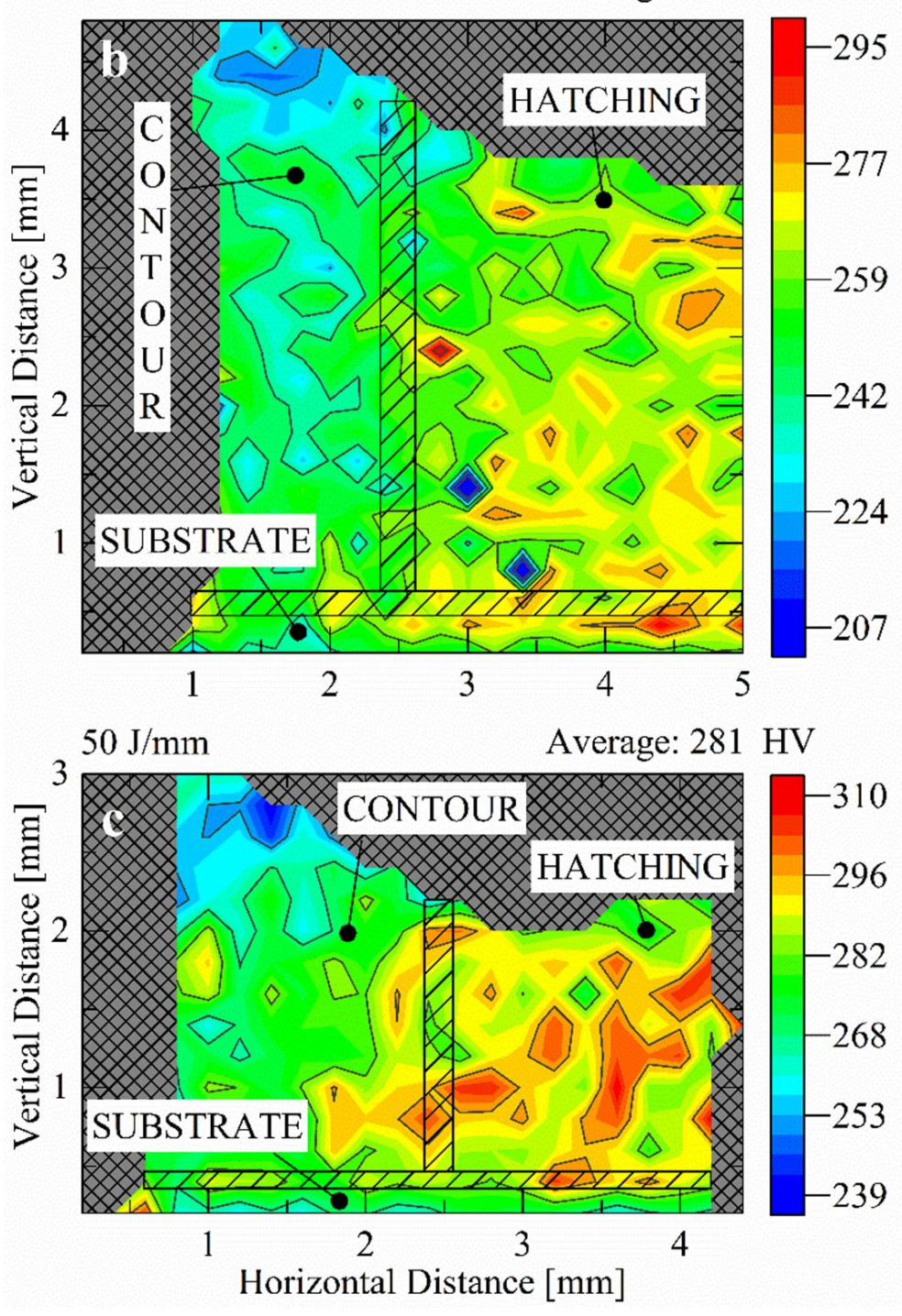


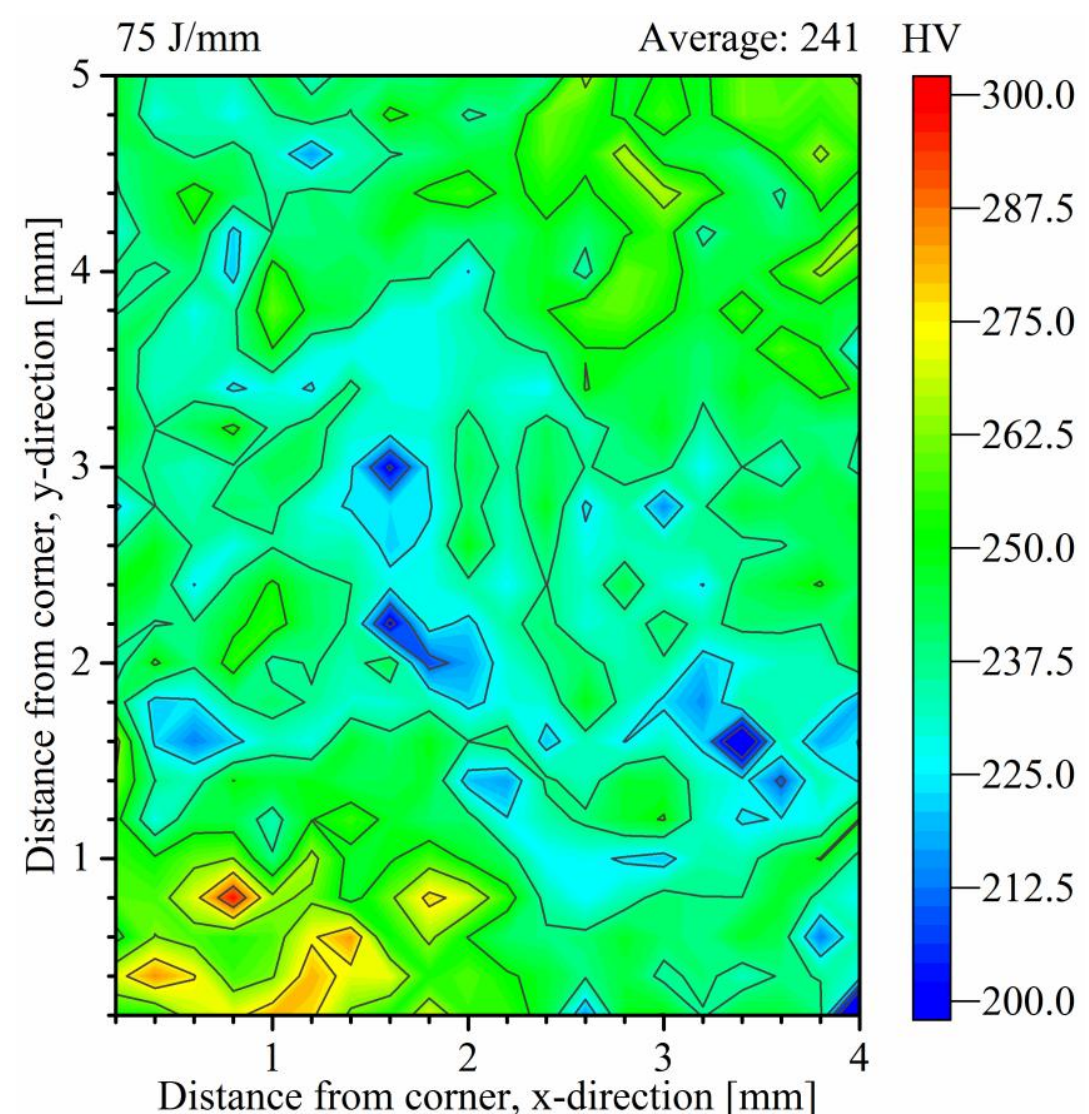

Distance from corner, $\mathrm{x}$-direction [mm] 

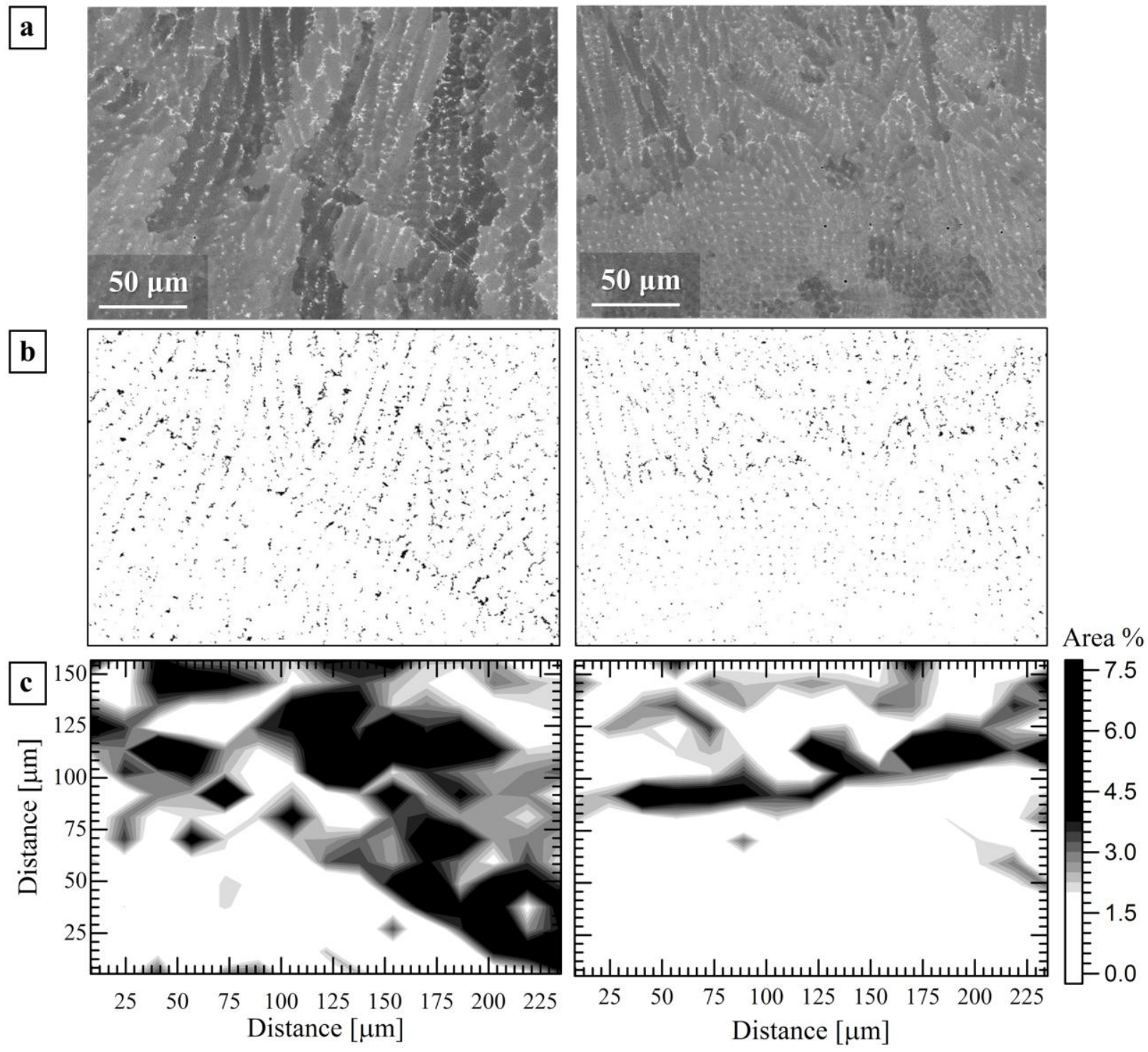


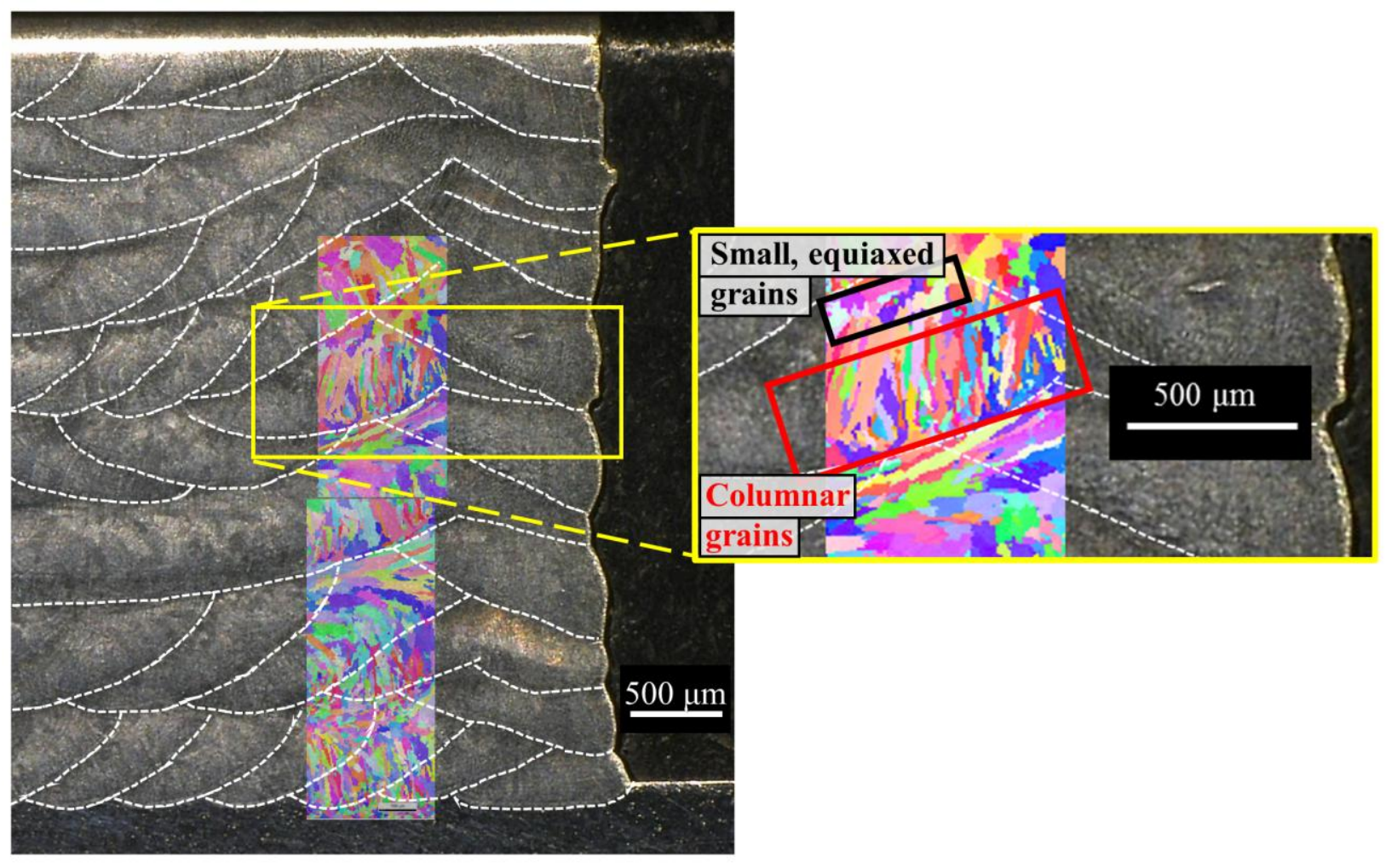




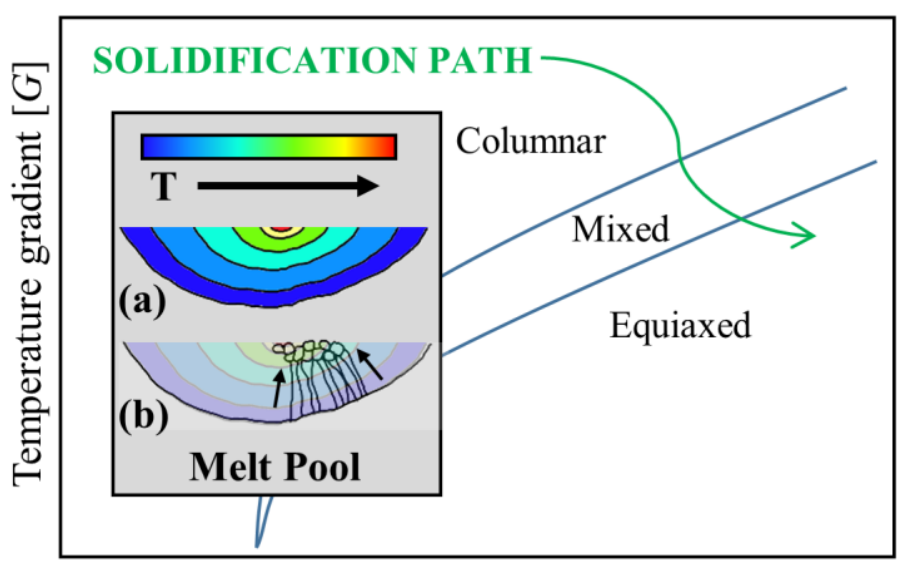

Solidification rate $[R]$ 
Direct laser deposition of alloy 718 cuboids
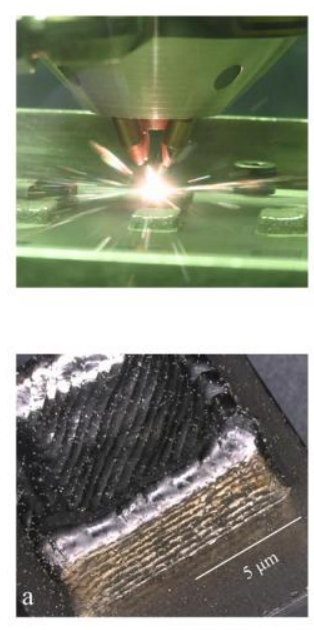

Grain microstructure and hardness mapping

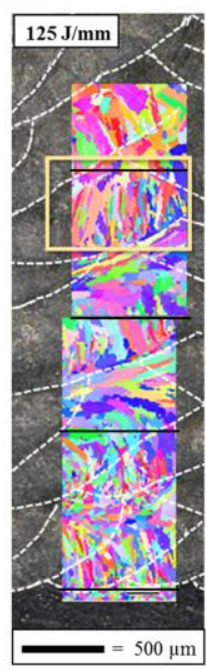

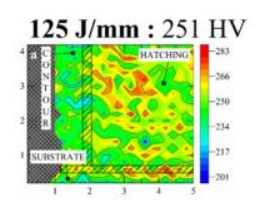

$75 \mathrm{~J} / \mathrm{mm}: 255 \mathrm{HV}$

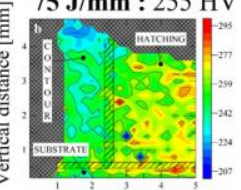

$50 \mathrm{~J} / \mathbf{m m}: 281 \mathrm{HV}$

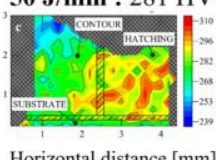

Laves phase distribution analysis

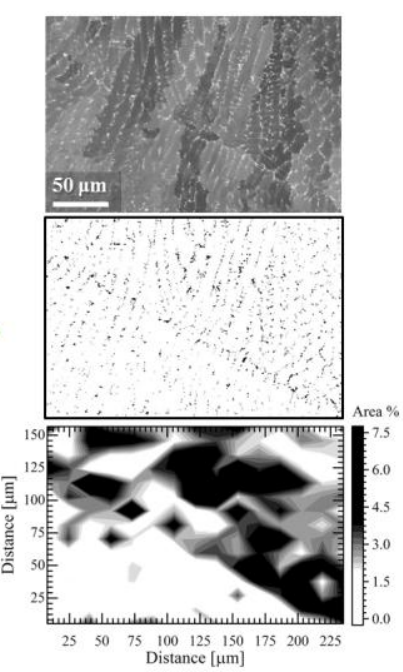

